\title{
Do Hospital Doctors Screen for Diabetes?
}

\author{
Authors \\ Marie Méan, Gérard Waeber, Pedro Marques-Vidal
}

\author{
Affiliation \\ Department of Internal Medicine, Internal Medicine, \\ Lausanne University Hospital, Lausanne, Switzerland \\ Key words \\ diabetes mellitus, pre-diabetes, HbA1c measurement, \\ in-hospital screening \\ received $\quad 04.01 .2018$ \\ revised $\quad 13.03 .2018$ \\ accepted 27.03.2018 \\ Bibliography \\ DOI https://doi.org/10.1055/a-0598-4682 \\ Published online: 8.10.2018 \\ Exp Clin Endocrinol Diabetes 2019; 127: 511-516 \\ (c) J. A. Barth Verlag in Georg Thieme Verlag KG Stuttgart . \\ New York \\ ISSN 0947-7349 \\ Correspondence \\ Dr. Marie Méan \\ Division of Internal Medicine \\ Lausanne University Hospital \\ Rue du Bugnon 46 \\ 1011 Lausanne, Switzerland \\ Tel.: + 41/21/314 1111 \\ marie.mean@chuv.ch
}

\begin{abstract}
Background One in five hospitalized patients presents with previously undetected diabetes mellitus (DM). We assessed whether hospital doctors measure $\mathrm{HbA}_{1} \mathrm{C}$ in hospitalized patients and act consequently.

Methods Data from patients hospitalized between January 2013 and December 2014 in a Swiss teaching hospital was collected. We assessed the frequency of $\mathrm{HbA} 1 \mathrm{c}$ measurements and the number of newly detected prediabetes or DM. We also examined whether $\mathrm{HbA} 1 \mathrm{c}$ values were associated with the antidiabetic drugs prescription and reporting of DM in the discharge letter.

Results Of the 2618 patients studied, 298 (11.4\%) had $\mathrm{HbA}_{1} \mathrm{C}$ measured, of whom 136 (45.6\%) had no previous history of DM. Of the 136 patients without history of DM, 51 (37.5\%) had prediabetic state and $23(16.9 \%)$ had DM. Newly detected prediabetes or DM were reported in $5.8 \%(3 / 51)$ and $65.8 \%$ of cases (15/23), respectively. Only half of patients $(11 / 23,47.8 \%)$ with newly detected DM received antidiabetic drug treatment at discharge. Patients with newly detected DM $(n=23)$ had a longer length of stay (median and interquartile range: 16 [9-25] versus $10[8-16]$ days, $p=0.028$ ) compared to patients without DM, while no such differences were found regarding in-hospital mortality.

Conclusions Hospital doctors seldom prescribe HbA1c measurement in medical hospitalized patients. Prescription of $\mathrm{HbA}_{1} \mathrm{C}$ measurement leads to a high detection rate ( $53 \%$ ) of (pre)DM among patients unaware of their status, but management and reporting of these conditions at discharge could be further improved.
\end{abstract}

\section{Introduction}

In Switzerland, one out of sixteen persons aged between 35 and 75 years has diabetes mellitus (DM), and almost one third of subjects with diabetes is unaware of their status [1,2]. Identification of patients with previously undiagnosed DM improves care and is cost-effective [3]. Since 2009, measurement of haemoglobin $A_{1} C$ $\left(\mathrm{HbA}_{1} \mathrm{c}\right)$ is recommended both to screen and to diagnose DM $[4,5]$.

Two studies conducted in the United States have suggested that in-hospital DM testing might be more effective than community detection, because the prevalence of DM among hospitalized patients is higher (approximately $35 \%$ in a general internal medicine service) [6, 7]. Such systematic screening might detect a previously unknown DM in $18 \%$ to $24 \%$ of hospitalized patients [6, 7].
As the prevalence of DM is lower in Europe than in the United States [8], it was expectable that DM detection among hospitalized patients might also be lower. Interestingly, a recent study conducted in a German university hospital showed that this hypothesis was partially wrong [9]. Actually, among patients hospitalized in internal medicine, the prevalence of DM was $32 \%$ and up to $7 \%$ of them had a newly diagnosed DM [9]. Thus, among medical hospitalized patients, in-hospital DM screening might be as effective in Europe as in the United States.

Because few information exists regarding current in-hospital DM screening, we aimed to assess: 1) whether hospital doctors measure $\mathrm{HbA1c}$ in medical patients hospitalized in a Swiss teaching hospital, 2) the prevalence of newly detected prediabetes and 
DM and 3) whether newly detected prediabetes and DM are managed and reported at discharge.

\section{Methods}

\section{Setting and sampling}

The study was conducted in the Lausanne University Hospital (CHUV), one of the five medical teaching hospitals in Switzerland. The CHUV has over 1400 beds and receives over 45,000 hospitalizations per year (www.chuv.ch). We considered all adult ( $\geq 18$ years) hospitalizations occurring in the division of general internal medicine between January 2013 and December 2014 who gave their informed consent to use their medical data (40\% in 2014).

Data from hospital electronic files between 2002 and 2014 was collected. Patients were categorized according to absence or presence of a history of DM. History of DM was defined as: 1) the presence of ICD-10 codes E10.x to E14.x ( $x$ = any number) in the medical files; 2 ) one glucose measurement > $11.8 \mathrm{mmol} / \mathrm{L}(213 \mathrm{mg} / \mathrm{dL})$; 3) $\mathrm{HbA}_{1} \mathrm{c} \geq 6.5 \%(47.5 \mathrm{mmol} / \mathrm{mol})$, and 4$)$ any anti-diabetic treatment at admission.

\section{Data collection and outcomes}

Socio-demographic data included age; gender; marital status (single/married or cohabitating/divorced/widowed); nationality (Swiss/non-Swiss); housing (own house/nursing home/ other) and private health insurance (yes/no). Hospital data included day of admission, total length of stay, and time spent in the emergency ward.

Clinical data included treated hypertension (based on medical records); smoking (past or current); obesity (based on ICD-10 codes E66.x); personal history of cardiovascular disease (medication at admission or on medical records); dyslipidemia [medication at admission, medical records, or fasting triglyceride $>2.82 \mathrm{mmol} / \mathrm{L}$ ( $250 \mathrm{mg} / \mathrm{dL}$ ) associated to a HDL-cholesterol< $0.9 \mathrm{mmol} / \mathrm{L}$ (35 mg/ $\mathrm{dL}$ )] and kidney disease (estimated glomerular filtration rate eGFR $<30 \mathrm{ml} / \mathrm{min} / \mathrm{m}^{2}$ according to Cockroft-Gault formula). Biological data included serum $\mathrm{HbA}_{1} \mathrm{c}, \mathrm{HDL}$-cholesterol, triglycerides, creatinin and glucose. Two glucose values measured during the study period were considered: 1) first glucose assessment and 2) highest value during hospitalization. Hba1c levels were assessed in EDTA whole blood using Bio-Rad D-100TM HbA1c testing system (Bio-Rad Laboratories, Hercules, CA, USA) [10]. As only seven patients had two HbA1c measurements during their stay, only the first $\mathrm{HbA}_{1} \mathrm{c}$ measurement was considered.

Outcomes included newly detected prediabetes or DM, the presence of an antidiabetic drug treatment at discharge, the length of stay and in-hospital mortality. A newly detected DM was defined as $\mathrm{HbA}_{1} \mathrm{c} \geq 6.5 \%$ (47.5 mmol$\left./ \mathrm{mol}\right)$ within patients with no history of DM. We considered that patients had a prediabetic state if $\mathrm{HbA}_{1} \mathrm{C}$ ranged between $\geq 5.7(38.8 \mathrm{mmol} / \mathrm{mol}$ ) and $<6.5 \%$ (47.5 mmol/ mol) according to the American Diabetes Association [4]. We also assessed whether newly detected prediabetes or DM were reported at discharge, based on ICD-10 codes E10.x to E14.x in the electronic medical file.

\section{Ethical considerations and data protection}

Since January 2013, all patients hospitalized in the CHUV are asked for general consent that allows future use of medical records and blood tests performed during their hospitalization. The study was approved by the ethics committee and no further specific consent from the patients was required as only already available administrative data was used.

Data was extracted by a dedicated team using the inclusion criteria defined previously and was anonymized before being provided to the investigators. Thus, it was not possible to assess how many patients were excluded.

\section{Statistical analyses}

Statistical analysis was conducted using Stata version 14.0 for windows (Stata corp, College Station, TX, USA). The prevalence of diabetes testing was assessed overall and according to presence/absence of previously known DM. Results were expressed as number of patients (percentage), mean \pm standard deviation or median [interquartile range] as appropriate. Bivariate comparisons were performed using chi-square or Fisher's exact test for categorical variables and Student's t-test or nonparametric Kruskal-Wallis test for continuous variables. Statistical significance was considered for a two-sided test $\mathrm{p}$-value $<0.05$.

\section{Results}

Overall, 2618 patients were included, 481 (18.4\%) of whom had a history of DM. Patients with DM were significantly older, less frequently Swiss nationals, presented with more cardiovascular risk factors and stayed longer in the emergency department at admission than patients without known DM (

\section{Do hospital doctors measure $\mathrm{HbA}_{1} \mathrm{c}$ in hospitalized patients?}

Overall, $\mathrm{HbA}_{1} \mathrm{c}$ was measured in 298 (11.4\%) patients, thereof 136 (45.6\%) had no history of DM. Median [interquartile range] $\mathrm{HbA}_{1} \mathrm{C}$ was 6.3 [5.6-7.6]\% (45.4 [37.7-59.6] mmol/mol) ( Fig. 1, panel A). Of the 481 patients with known DM, $162(33.6 \%)$ had $\mathrm{HbA}_{1} \mathrm{c}$ measured. Median [interquartile range] $\mathrm{HbA}_{1} \mathrm{C}$ among these patients was 7.2 [6.2-8.5]\% (55.2 [44.3-69.4] mmol/mol) (• Fig. 1, panel B). Of the 2137 patients without known DM, 136 (6.4\%) had $\mathrm{HbA}_{1} \mathrm{C}$ measured. Median [interquartile range] $\mathrm{HbA}_{1} \mathrm{C}$ among these pa-

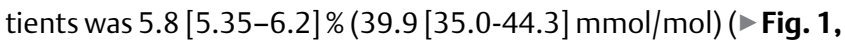
panel C).

Restricting the analysis to patients without history of DM, significantly higher frequencies of history of cardiovascular disease and hypertension, and a higher glucose levels and a lower frequency of kidney disease were found in patients with $\mathrm{HbA}_{1} \mathrm{c}$ measurement, while no significant differences were found for gender, age, and history of dyslipidemia ( $\triangleright$ Table 2 ).

\section{Prevalence of newly detected prediabetes and diabetes mellitus}

Of the 136 (6.4\%) patients without history of DM and who had $\mathrm{HbA}_{1} \mathrm{C}$ measured, 51 (37.5\%) had a prediabetic state and 23 (16.9\%) had DM. Baseline characteristics did not differ between patients with newly diagnosed prediabetes, newly diagnosed DM 
- Table 1 Patients' characteristics overall and according to previous history of diabetes mellitus.

\begin{tabular}{|c|c|c|c|c|}
\hline & \multirow{2}{*}{ All $(n=2618)$} & \multicolumn{2}{|c|}{ History of diabetes mellitus ${ }^{*}$} & \multirow{2}{*}{ p-value } \\
\hline & & Absent $(n=2137)$ & Present $(n=481)$ & \\
\hline Age, years & $68.4 \pm 16.7$ & $67.6 \pm 17.4$ & $72 \pm 12.7$ & $<0.001$ \\
\hline Age $\geq 65$ years $(\%)$ & $1653(63.1)$ & $1303(61.0)$ & $350(72.8)$ & $<0.001$ \\
\hline Female gender (\%) & $1187(45.3)$ & $1005(47.0)$ & $182(37.8)$ & $<0.001$ \\
\hline Marital status (\%) & & & & 0.074 \\
\hline Single & $365(14.4)$ & $316(15.2)$ & $49(10.8)$ & \\
\hline Married/cohabitating & $1189(46.9)$ & $970(46.7)$ & $219(48.1)$ & \\
\hline Divorced & $453(17.9)$ & $372(17.9)$ & $81(17.8)$ & \\
\hline Widowed & $527(20.8)$ & $421(20.3)$ & $106(23.3)$ & \\
\hline Coming from home (\%) & $2093(80.0)$ & $1685(78.9)$ & $408(84.8)$ & 0.003 \\
\hline Private health insurance (\%) & $128(4.9)$ & $111(5.2)$ & $17(3.5)$ & 0.127 \\
\hline Obesity (\%) & $58(2.2)$ & $5(0.2)$ & $53(11.0)$ & $<0.001$ \\
\hline Hypertension (\%) & $199(7.6)$ & $56(2.6)$ & $143(29.7)$ & $<0.001$ \\
\hline Past or current smoking (\%) & $23(0.9)$ & $6(0.3)$ & $17(3.5)$ & $<0.001$ \\
\hline History of cardiovascular disease (\%) & $1352(51.6)$ & $958(44.8)$ & $394(81.9)$ & $<0.001$ \\
\hline History of dyslipidemia (\%) & $657(25.1)$ & $395(18.5)$ & $262(54.5)$ & $<0.001$ \\
\hline $\mathrm{eGFR}<30 \mathrm{ml} / \mathrm{min} / \mathrm{m}^{2}(\%)$ & $242(11.8) \ddagger$ & $175(10.6)$ & $67(16.8)$ & 0.001 \\
\hline Glucose level at admission $(\mathrm{mmol} / \mathrm{l}) \S$ & $6.3 \pm 3.0$ & $6.3 \pm 3.0$ & $7.9 \pm 3.8$ & $<0.001$ \\
\hline Time spent in emergency department (hours) & $9[5-16]$ & $9[5-16]$ & $10[7-18]$ & $0.002 \dagger$ \\
\hline \multicolumn{5}{|c|}{$\begin{array}{l}{ }^{*} \text { History of diabetes mellitus was based on ICD-10 codes E10.x- E14.x, any anti-diabetic medicines or a history of abnormal glucose homeostasis. } \S \text {, } \\
n=108 \text { (present) and } n=390 \text { (absent). eGFR, estimated glomerular filtration rate as assessed by the Cockroft-Gault formula. Results are expressed as } \\
\text { number of participants (column \%), as average } \pm \text { SD or as median and [interquartile range]. Statistical analysis by chi-square for categorical data and } \\
\text { by Student's t-test of Kruskal-Wallis ( } \dagger \text { ) test for continuous data. }\end{array}$} \\
\hline 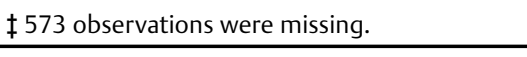 & & & & \\
\hline
\end{tabular}

and those without DM, with the exception that patients with newly detected DM had a higher glucose level at admission ( $>$ Table 3 ).

\section{How are newly detected prediabetes and DM managed and reported at discharge?}

Among the 23 patients with newly detected DM, 16 (69.6\%) had an $\mathrm{HbA}_{1} \mathrm{C} \geq 7 \%$ ( $53.0 \mathrm{mmol} / \mathrm{mol}$ ) ( $>$ Fig. 1, panel C). Patients with a newly detected DM had a longer length of stay, while no differences were found regarding in-hospital mortality ( $>$ Table 3). Eleven of them ( $48 \%$ ) received anti-diabetic treatment at discharge. Also at discharge, newly detected prediabetes or DM were reported in $5.8 \%$ (3/51) and $65.8 \%$ of cases (15/23), respectively.

\section{Discussion}

In a Swiss teaching hospital, doctors seldom prescribed HbA1c measurement: slightly over one tenth (11.4\%) of medical hospitalized patients. This percentage was even lower $(6.4 \%)$ in medical patients without known DM. Interestingly, a prediabetic state was found in $37.5 \%$ of patients and DM was detected in one of five. Indicating that when a physician asks for $\mathrm{HbA} 1 \mathrm{c}$ measurement, the likelihood of detecting (pre)DM is high (roughly $50 \%$ ). However, prescribers tended to underreport these newly detect (pre)diabetic states.

\section{To which hospitalized patients do hospital doctors prescribe $\mathrm{HbA}_{1} \mathrm{C}$ measurement?}

According to the 2013 update of the Standards of Medical Care in Diabetes by the American Diabetes Association, testing for DM should be considered for all adults with overweight (body mass index $>25 \mathrm{~kg} / \mathrm{m}^{2}$ ) and at least one of the known risk factors for DM such as physical inactivity; first-degree relative with DM; high risk race/ethnicity; hypertension ( $\geq 140 / 90 \mathrm{mmHg}$ or on therapy); $\mathrm{HDL}<0.9 \mathrm{mmol} / \mathrm{l}$ and/or triglycerides $>2.82 \mathrm{mmol} / \mathrm{l}$; gestational diabetes or high weight newborn; women with polycystic ovary syndrome; history of cardiovascular disease and $\mathrm{HbA}_{1} \mathrm{c} \geq 5.7 \%$ (38.8 mmol$/ \mathrm{mol}$ ) on previous testing [4]. In our study, hospital doctors prescribed $\mathrm{HbA}_{1} \mathrm{c}$ measurement more often for patients with clinical factors associated with greater risks of cardiovascular disease. The utilization of $\mathrm{HbA}_{1} \mathrm{c}$ among hospitalized patients seems to be in accordance with guidelines.

Interestingly, a recent study conducted in the ambulatory setting showed that it was possible to half the number of patients needed to invite to screen by using electronical medical data in a two-step procedure [11]. Patients without DM risk or with DM screening within the past 3 years were not considered for screening. Further studies assessing the performance of opportunistic inhospital DM screening using electronical medical records and such are needed.

Hospital doctors prescribed $\mathrm{HbA}_{1} \mathrm{c}$ measurement to $11.4 \%$ of all medical patients, but only to $6.4 \%$ of patients with no history of DM. In a German study, hospital doctors prescribed HbA1c measurement to surgical and medical adults slightly more often (16\% of all patients and $10 \%$ of patients with no history of DM), but the prescription rates for medical patients was not specified. A Canadian study reported that $14.2 \%$ of non-diabetic primary care patients aged 45 or more had at least one $\mathrm{HbA}_{1} \mathrm{C}$ measurement dur- 


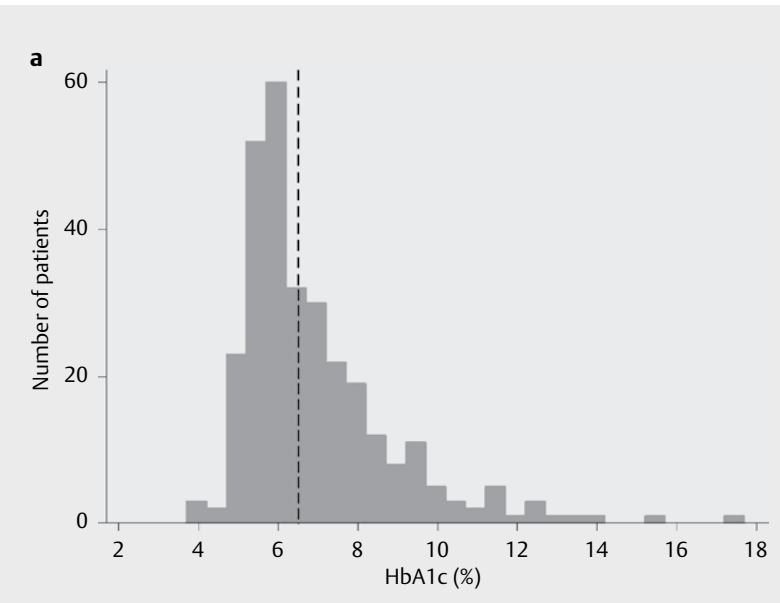

b

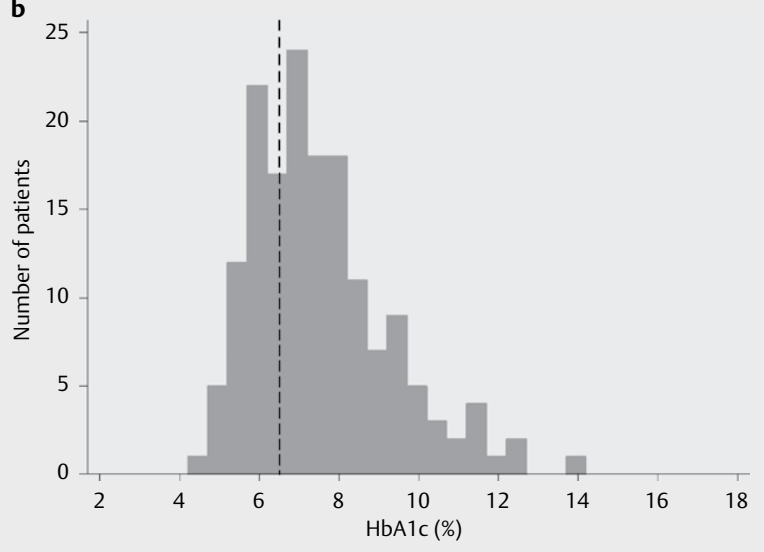

c

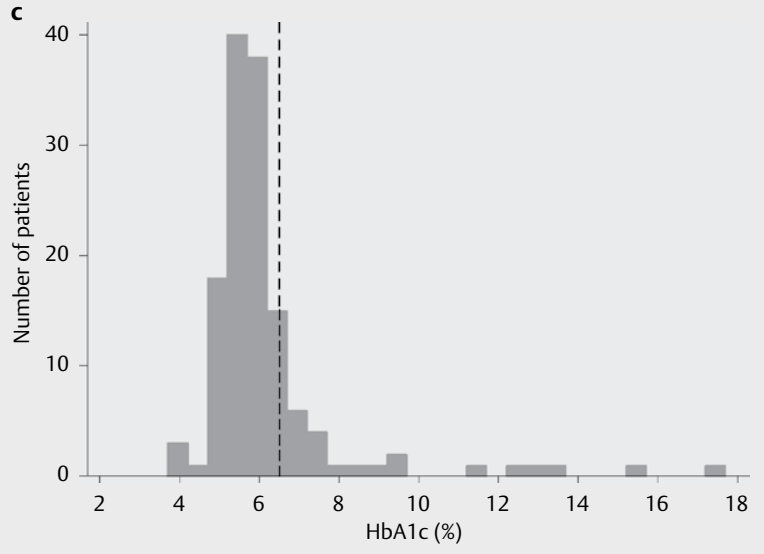

- Fig. 1 Distribution of $\mathrm{HbA}_{1} \mathrm{c}$ values. Panel A: all patients; panel B: patients with known diabetes mellitus (based on ICD-10 codes E10.xE14.x, any anti-diabetic medicines or a history of abnormal glucose homeostasis); panel C: patients without history of diabetes mellitus. Dashed line indicates an $\mathrm{HbA}_{1} \mathrm{c}$ value of $6.5 \%(47.5 \mathrm{mmol} / \mathrm{mol})$

ing a three years period [12]. Indeed, most studies conducted on hospitalized patients used $\mathrm{HbA}_{1} \mathrm{c}$ as part of a systematic detection strategy $[6,7,13]$ or focused on patients with a known DM $[14,15]$. Still, the Canadian study was performed prior to the release of the current guidelines [4,5] and because the rates of $\mathrm{HbA}_{1} \mathrm{C}$ measurement tended to increase since 2009 [13], the frequency of $\mathrm{HbA}_{1} \mathrm{C}$ measurement in medical non-diabetic hospitalized patients might be at least twice less frequent than in primary care patients with-
- Table 2 Clinical characteristics of hospitalized patients without history of diabetes mellitus, according to presence or absence of $\mathrm{HbA} 1 \mathrm{c}$ measurement.

\begin{tabular}{|l|c|c|r|}
\hline & $\begin{array}{c}\text { Not measured } \\
(\mathbf{n = 2 0 0 1 )}\end{array}$ & $\begin{array}{c}\text { Measured } \\
(\mathbf{n = 1 3 6 )}\end{array}$ & P-value \\
\hline Age, years & $67.6 \pm 17.5$ & $66.6 \pm 16.0$ & 0.514 \\
\hline Age $\geq 65$ years (\%) & $1227(61.3)$ & $76(55.9)$ & 0.208 \\
\hline Female gender (\%) & $949(47.4)$ & $56(41.2)$ & 0.158 \\
\hline Hypertension (\%) & $25(1.3)$ & $31(22.8)$ & $<0.001$ \\
\hline $\begin{array}{l}\text { History of cardiovas- } \\
\text { cular disease (\%) }\end{array}$ & $876(43.8)$ & $82(60.3)$ & $<0.001$ \\
\hline $\begin{array}{l}\text { Dyslipidemia (\%) } \\
\text { eGFR<30 ml/min/m² } \\
\text { (\%) }\end{array}$ & $363(18.1)$ & $32(23.5)$ & 0.117 \\
\hline $\begin{array}{l}\text { Glucose level at } \\
\text { admission (mmol/I) }\end{array}$ & $6.1 \pm 1.7$ & $6(4.6)$ & 0.020 \\
\hline
\end{tabular}

Results are expressed as number of patients (column \%) or as average \pm standard deviation. Between-group comparisons performed using chi-square for categorical data and by Student's t-test for continuous data. ' among 55 and 335 patients with and without measurement, respectively.

out DM. Overall, our results suggest that DM screening is seldom performed in a teaching hospital setting.

\section{Prevalence of newly detected prediabetes and diabetes mellitus}

Among hospitalized patients without history of $\mathrm{DM}, \mathrm{HbA}_{1} \mathrm{C}$ measurement allowed detecting prediabetes in $37.5 \%$ and DM in $16.9 \%$. Two studies conducted in the United States have suggested that in-hospital DM testing might be more effective than community detection, because the prevalence of DM among hospitalized patients is higher. The first one showed that $35 \%$ of patients admitted to hospital had DM, compared to $9.3 \%$ in the general population [6]. The second reported that $18 \%$ of hospitalized patients presented with previously undetected $\mathrm{DM}$, defined as $\mathrm{HbA}_{1} \mathrm{c}>6.1 \%$ (43.2 $\mathrm{mmol} / \mathrm{mol}$ ) [7]. In this study, the prevalence of DM among patients with $\mathrm{HbA}_{1} \mathrm{c}$ measurements was almost three fold higher than the one reported in the general population using fasting plasma glucose levels [2].

\section{How are newly detected prediabetes and DM managed and reported at discharge?}

Hospital doctors underreported newly detected prediabetic state and DM at discharge, precluding further $\mathrm{HbA}_{1} \mathrm{C}$ control as recommended by guidelines and good quality of care [4]. Still, the underreporting rate of DM in our study ( $40 \%$ ) was lower than in a previous Canadian study, which was approximately $80 \%$ [16]. Nowadays, at discharge, systematic report regarding whether an Hba1c was performed and its corresponding result could be easily achieved using electronical medical records.

Similarly, antidiabetic drug treatment was prescribed to only half ( $48 \%$ ) of new detected DM cases, a value comparable to a study conducted in the Swiss general population (53.3\% in 2007) [17] but lower than in a study conducted in Lausanne (86\%)[2].

In our study, hospital doctors were three times more likely to prescribe $\mathrm{HbA}_{1} \mathrm{c}$ in patients with a known $\mathrm{DM}$, as if they were more 
- Table 3 Factors associated with abnormal glucose homeostasis in hospitalized patients without history of diabetes at admission/discharge and with $\mathrm{HbA}_{1} \mathrm{c}$ measurement $(\mathrm{n}=136)$.

\begin{tabular}{|c|c|c|c|c|}
\hline At admission & $\begin{array}{l}\text { No diabetes } \\
(\mathrm{N}=62)\end{array}$ & $\begin{array}{l}\text { Newly detected prediabetes * } \\
\qquad(\mathrm{n}=\mathbf{5 1})\end{array}$ & $\begin{array}{l}\text { Newly detected diabetes } \uparrow \\
\qquad(\mathrm{N}=23)\end{array}$ & P-value \\
\hline Age, years & $64.6 \pm 17.3$ & $68.5 \pm 14.8$ & $68 \pm 14.7$ & 0.388 \\
\hline Age $\geq 65$ years $(\%)$ & $32(51.6)$ & $33(64.7)$ & $11(47.8)$ & 0.263 \\
\hline Female gender (\%) & $29(46.8)$ & $21(41.2)$ & $6(26.1)$ & $0.226 !$ \\
\hline Coming from home (\%) & $59(95.2)$ & $48(94.1)$ & $22(95.7)$ & $1.000 \vdots$ \\
\hline Obesity (\%) & $3(4.8)$ & $1(2.0)$ & $0(0)$ & $0.660 \vdots$ \\
\hline Hypertension (\%) & $12(19.4)$ & $11(21.6)$ & $8(34.8)$ & $0.326 \vdots$ \\
\hline Past or current smoking (\%) & $1(1.6)$ & $2(3.9)$ & $0(0)$ & $0.765 !$ \\
\hline History of cardiovascular disease (\%) & $33(53.2)$ & $33(64.7)$ & $16(69.6)$ & 0.282 \\
\hline Dyslipidemia (\%) & $14(22.6)$ & $11(21.6)$ & $7(30.4)$ & 0.687 \\
\hline $\mathrm{eGFR}<30 \mathrm{ml} / \mathrm{min} / \mathrm{m}^{2}(\%)$ & $1(1.7)$ & $2(4.0)$ & $3(13.6)$ & $0.098 \vdots$ \\
\hline Glucose level at admission $(\mathrm{mmol} / \mathrm{l}) \#$ & $5.2 \pm 1.0$ & $5.7 \pm 1.1$ & $14.7 \pm 11.2$ & $<0.001$ \\
\hline $\begin{array}{l}\text { Time spent in emergency department } \\
\text { (hours) }\end{array}$ & $21[10-28]$ & $20[6-27]$ & $11[7-25]$ & $0.320 \S$ \\
\hline \multicolumn{5}{|l|}{ At discharge } \\
\hline Length of stay (days) & $13[8-19]$ & $8[6-11]$ & $16[9-25]$ & $0.002 \S$ \\
\hline In-hospital mortality (\%) & $0(0)$ & $1(2.0)$ & $1(4.4)$ & $0.155 !$ \\
\hline Anti-diabetic treatment at discharge (\%) & $1(1.6) \S$ & $0(0)$ & $11(47.8)$ & $<0.001$ \\
\hline Reported in medical file & NA & $3(5.8)$ & $15(65.8)$ & NA \\
\hline \multicolumn{5}{|c|}{ Abbreviations: eGFR: estimated glomerular filtration rate as assessed by the Cockroft-Gault formula; NA: does not apply. } \\
\hline \multicolumn{5}{|c|}{ * Prediabetes defined as: HbA1c between $\geq 5.7(38.8 \mathrm{mmol} / \mathrm{mol})$ and $<6.5 \%(47.5 \mathrm{mmol} / \mathrm{mol})$. } \\
\hline \multicolumn{5}{|c|}{$\begin{array}{l}\dagger \text { Newly diagnosed diabetes defined as } \mathrm{HbA} 1 \mathrm{c} \geq 6.5 \% \text {. } \S \text { This patient received metformin for a metabolic syndrome without diabetic state (Hba } 1 \mathrm{c} \text { value } \\
5.2 \% \text { ). \# for } 26,16 \text { and } 13 \text { patients with no diabetes, newly detected prediabetes and newly detected diabetes, respectively }\end{array}$} \\
\hline
\end{tabular}

concerned by the quality of DM care than by hospital DM screening. This finding is in accordance with a study performed in a German hospital, where $34 \%$ of patients with a known DM had a $\mathrm{HbA}_{1} \mathrm{C}$ measurement [9]. Hence, delivering DM prevention in asymptomatic patients requires skills that traditionally trained clinicians may not possess [18]. Thus, hospital DM detection needs to be coupled with resources for physician education and management in the outpatient setting.

\section{Strengths and limitations}

There is little information regarding in-hospital DM screening and management of newly detected DM in hospitalized medical patients outside English-speaking countries. Hence, our data provide important information for the public health management of DM in Europe.

Our study also has several limitations. Firstly, the detection of (pre)DM could only be achieved in the sample of patients who benefited from $\mathrm{HbA}_{1} \mathrm{c}$ measurement. Thus, whether the current practice of $\mathrm{HbA} 1 \mathrm{c}$ measurement in our teaching hospital is sufficient and effective needs to be further studied. Although our results cannot be generalized to the total population of hospitalized medical patients, still they indicate that when a doctor asks for $\mathrm{HbA}_{1} \mathrm{c}$ measurement, the likelihood of detecting (pre)DM is high. Secondly, we could not distinguish between DM type 1 and 2. However, because the prevalence of type $1 \mathrm{DM}$ is low, we assume that most of the cases of DM in our study were type $2 \mathrm{DM}$. Thirdly, some patients with a history of DM could have been missed. Still, we used a broad definition of DM history including ICD-10 codes in previous hospitalisations and glucose $>11.8 \mathrm{mmol} / \mathrm{L}(213 \mathrm{mg} / \mathrm{dL}), \mathrm{HbA}_{1} \mathrm{c} \geq 6.5 \%$ $(47.5 \mathrm{mmol} / \mathrm{mol})$ or any antidiabetic treatment at admission. Fourthly, a possible selection cannot be excluded, hospital doctors (un)consciously prescribing $\mathrm{HbA}_{1} \mathrm{c}$ measurements in patients who are more at risk of presenting with DM. Indeed, restricting the analysis to patients without history of DM, significantly higher frequencies of history of cardiovascular disease and hypertension and higher glucose levels and a lower frequency of kidney disease were found in patients with $\mathrm{HbA}_{1} \mathrm{C}$ measurement, while no significant differences were found for gender, age, and history of dyslipidemia ( $\triangleright$ Table 3). Fifthly, no information regarding lifestyle intervention was available in the electronic medical files. Hence, only drug interventions could be assessed. Finally, the reporting of newly detected (pre)DM was based on ICD-10 codes at discharge, and it is possible that results of $\mathrm{HbA}_{1} \mathrm{c}$ measurement might be present in the discharge letter but not coded in the medical record. Still, it has been shown that diabetes is adequately reported using ICD-10 codes in Switzerland [19], so we believe that ICD-10 codes could adequately characterize the conditions indicated in the discharge letter.

\section{Conclusions}

Hospital doctors do screen for diabetes, however they seldom prescribe HbA1c measurement in medical hospitalized patients with- 
out known DM. Because prescription of $\mathrm{HbA}_{1} \mathrm{c}$ measurement leads to a high detection rate ( $53 \%$ ) of (pre)DM among patients unaware of their status, management and reporting of these conditions at discharge could be further improved.

\section{Author's contribution}

MM conducted the study and wrote most of the article; PMV made the statistical analyses and wrote part of the article; GW revised the article for important intellectual content, PMV had full access to the data and is the guarantor of the study. All authors have read and approved this version of the article.

\section{Funding}

This study was funded by the Department of internal Medicine of Lausanne University Hospital. The funding sources had no involvement in study design; in the collection, analysis and interpretation of data; in the writing of the report; and in the decision to submit the article for publication.

\section{Conflict of Interest}

The authors declare that they have no conflict of interest.

\section{References}

[1] Firmann M, Mayor V, Vidal PM et al. The CoLaus study: A populationbased study to investigate the epidemiology and genetic determinants of cardiovascular risk factors and metabolic syndrome. BMC cardiovascular disorders 2008; 8: 6 doi:10.1186/1471-2261-8-6

[2] Kaiser A, Vollenweider P, Waeber $G$ et al. Prevalence, awareness and treatment of type 2 diabetes mellitus in Switzerland: The CoLaus study. Diabetic medicine: A journal of the British Diabetic Association 2012; 29: 190-197 doi:10.1111/j.1464-5491.2011.03422.x

[3] Kahn R, Alperin P, Eddy D et al. Age at initiation and frequency of screening to detect type 2 diabetes: A cost-effectiveness analysis. Lancet 2010; 375: 1365-1374 doi:10.1016/S0140-6736(09)62162-0

[4] [Anonymous]. Standards of medical care in diabetes--2014. Diabetes care 2014; 37: (Suppl 1): S14-S80 doi:10.2337/dc14-S014

[5] Saudek CD, Herman WH, Sacks DB et al. A new look at screening and diagnosing diabetes mellitus. The Journal of clinical endocrinology and metabolism 2008; 93: 2447-2453 doi:10.1210/jc.2007-2174

[6] Mazurek JA, Hailpern SM, Goring T et al Prevalence of hemoglobin A1C greater than $6.5 \%$ and $7.0 \%$ among hospitalized patients without known diagnosis of diabetes at an urban inner city hospital. The Journal of clinical endocrinology and metabolism 2010; 95: 13441348 doi:10.1210/jc.2009-1151
[7] Wexler DJ, Nathan DM, Grant RW et al. Prevalence of elevated hemoglobin A1c among patients admitted to the hospital without a diagnosis of diabetes. The Journal of clinical endocrinology and metabolism 2008; 93: 4238-4244 doi:10.1210/jc.2008-1090

[8] Guariguata L, Whiting DR, Hambleton I et al. Global estimates of diabetes prevalence for 2013 and projections for 2035. Diabetes research and clinical practice 2014; 103: 137-149 doi:10.1016/j. diabres.2013.11.002

[9] Kufeldt ], Kovarova M, Adolph M et al. Prevalence and Distribution of Diabetes Mellitus in a Maximum Care Hospital: Urgent Need for HbA1c-Screening. Exp Clin Endocrinol Diabetes 2017, doi:10.1055/s-0043-112653

[10] Maesa JM, Fernandez-Riejos P, Mora CS et al. Evaluation of Bio-Rad D-100 HbA1c analyzer against Tosoh G8 and Menarini HA-8180 V. Pract Lab Med 2016; 5: 57-64 doi:10.1016/j.plabm.2016.05.002

[11] Vrca Botica M, Carkaxhiu L, Kern J et al. How to improve opportunistic screening by using EMRs and other data. The prevalence of undetected diabetes mellitus in target population in Croatia. Public Health 2017; 145: 30-38 doi:10.1016/j.puhe.2016.12.008

[12] Greiver M, Aliarzadeh B, Moineddin R et al. Diabetes screening with hemoglobin A1c prior to a change in guideline recommendations: Prevalence and patient characteristics. BMC family practice $2011 ; 12$ : 91 doi:10.1186/1471-2296-12-91

[13] Valentine NA, Alhawassi TM, Roberts GW et al. Detecting undiagnosed diabetes using glycated haemoglobin: An automated screening test in hospitalised patients. The Medical journal of Australia 2011; 194 : 160-164

[14] Snir A, Dabin B, Hyun K et al. Glycosylated haemoglobin assessment in diabetic patients with acute coronary syndromes. Internal medicine journal 2016; 46: 574-582 doi:10.1111/imj.13038

[15] Strack B, DeShazo JP, Gennings C et al. Impact of HbA1c measurement on hospital readmission rates: analysis of 70,000 clinical database patient records. BioMed research international 2014; 2014: 781670 doi:10.1155/2014/781670

[16] Malcolm JC, Kocourek J, Keely E et al. Implementation of a screening program to detect previously undiagnosed dysglycemia in hospitalized patients. Canadian journal of diabetes 2014; 38: 79-84 doi: 10.1016/j. jcjd.2014.02.005

[17] Estoppey D, Paccaud F, Vollenweider P et al. Trends in self-reported prevalence and management of hypertension, hypercholesterolemia and diabetes in Swiss adults, 1997-2007. BMC Public Health 2011; 11: 114 doi:10.1186/1471-2458-11-114

[18] Saaristo T, Peltonen M, Keinanen-Kiukaanniemi S et al. National type 2 diabetes prevention programme in Finland: FIN-D2D. International journal of circumpolar health 2007; 66: 101-112

[19] Zellweger U, Bopp M, Holzer BM et al. Prevalence of chronic medical conditions in Switzerland: Exploring estimates validity by comparing complementary data sources. BMC Public Health 2014; 14: 1157 doi:10.1186/1471-2458-14-1157 